\section{IINIVFRSITÏT}

UNIVERSITÄT

$D_{E} U_{S} I_{S} S^{B}{ }_{N} U R$ G
Chair for Management Sciences and Energy Economics

Prof. Dr. Christoph Weber

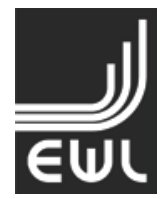

Chair for Management Sciences and Energy Economics University of Duisburg-Essen

EWL Working Paper No. 02/10

\title{
Appropriate Contract Durations in the German Markets for On-line Reserve Capacity by
}

Sebastian Just

August 16, 2010 


\title{
Appropriate Contract Durations in the German Markets for On-line Reserve Capacity
}

by Sebastian Just

\begin{abstract}
This paper explores the economic implications of different contract durations in markets for on-line (primary and secondary) reserve capacity in Germany with the crucial feature of separate markets for spot energy and reserve capacity provision. The analysis is based on an equilibrium model developed by Just and Weber (2008) for reserve markets. It reveals the implicit trade-off for the bidders and interdependencies between the reserve and the spot markets. The results clearly show that shorter periods (with resulting lower variations in overall electricity demand) lead to more efficient dispatch and market results. Not only prices in the reserve capacity markets are expected to be lower, but also spot market prices. As these benefits can be partially reaped by owners of large generation portfolios also under longer contract durations, it discriminates smaller generation companies and can potentially deter market participation. Further, the paper discusses security concerns against shorter contract durations. It is shown that the opportunity costs character of the reserve market implies sufficient incentives for supplying online reserve capacity. The concerns do not appear to be predominant and it should be possible to manage them appropriately.
\end{abstract}

Keywords : electricity markets, contract duration, power systems reserve, ancillary service, primary reserve, secondary reserve, spinning reserve, opportunity costs, equilibrium model

JEL-Classification : L94, L11, D41, D44

SEBASTIAN JUST

Chair for Management Sciences and Energy Economics,

University of Duisburg-Essen (Campus Essen)

Universitätsstr. 11, 45117 Essen

www.ewl.wiwi.uni-due.de

Sebastian.Just@bcg.com

The authors are solely responsible for the contents which do not necessarily represent the opinion of the Chair for Management Sciences and Energy Economics. 


\section{INTRODUCTION}

Electricity is a particular commodity. It is virtually non-storable and is provided by a large complex system that requires balancing of consumed and generated electricity in every moment. Any imbalance can only be corrected by real-time generation re-dispatch or more or less forced demand adjustments. ${ }^{1}$ Since there is no real-time electricity market in Germany, the deployment of reserve capacity is the only source for real-time balancing.

The balancing task is centralized with the transmission system operators (TSOs) to reflect its critical technical nature and its property as a public good. The TSOs are not able to provide the necessary reserve capacity themselves due to the unbundling required for competitive markets.

Like in most European markets, the electricity system in Germany is organized by various bilateral markets in contrast to coordinated pool models like FERC's Standard Market Design in most of the liberalized markets in the US. ${ }^{2}$ In essence, under the German bilateral market design, generation capacity can be basically marketed in two ways: selling the energy output in forward, day-ahead or intraday spot markets, or selling the capacity with the option for generation in the system reserve capacity market. ${ }^{3}$ Even if these markets are interrelated, there is no institutional coordination among them and they are run independently in Germany and most other European markets. ${ }^{4}$

System reserve capacity has to be procured by the German TSOs via auctions following an admonition by the German Cartel Office (see BKartA, 2000). The auction results and rules have been debated ever since (see Swider and Weber, 2003; Swider and Ellersdorfer, 2005; Büchner and Türkucar, 2005; Wawer, 2005 and Swider, 2007a). One of the issues rarely discussed is the appropriate contract duration.

Following the admonition, primary and secondary reserves were auctioned with contract durations of six months. During the subsequent discussions, the four German TSOs advocated for $50 \%$ yearly and $50 \%$ quarterly contracts. The German regulator BNetzA opted for shorter periods and decided finally to reduce the contract duration to one month starting from December 2007. It aims even at daily auctions in medium term.

Also internationally the picture is mixed for comparable reserve qualities. Hourly auctions are used in California and Spain. The Swedish TSO procures day-time, night-time, and weekend blocks on a weekly basis, supplemented by hourly bids. A monthly tendering process is utilized in UK. Longer time horizons are found e.g. in Hungary and in Belgium with half-

\footnotetext{
${ }^{1}$ System reserve capacity can be provided from the demand-side (usually large industrial customers) as well, but due to different restrictions, mainly technical ones, there are currently still difficulties to implement these measures widely in Germany (see Heise, 2007). However, load curtailment is used to force the system back into balance if supply-side measures are not sufficient. As load curtailment or load shedding is generally assumed very expensive (see Stoft, 2002), it is only used as the last resort before an unavoidable blackout.

${ }^{2}$ There are fundamental differences between the two market designs - one relying more on market interactions in multiple decentral markets and the other relying on the central coordination of all major activities through the system operator. Which of the two designs is generally more appropriate is not unambiguous (see Bower and Bunn 2001; Wilson, 2002; Ockenfels et al, 2008; Mansur and White, 2009) and is not focus of this paper.

${ }^{3}$ Note, in none of the European markets a forward capacity market exists yet like in the Northeastern US, which has the function to ensure enough investment installed capacity which is available for short-term energy (dayahead and intraday spot markets) and system reserve capacity provision.

${ }^{4}$ In contrast, pool models mostly co-optimize short-term energy and reserve capacity provision. This is usually done by the system operator using algorithms to optimize the system based on offers by the generators. In systems like PJM even transmission constraints are considered within the optimization algorithm.
} 
yearly and yearly contracts, respectively. Bi-lateral contracts in France run from two to three years (see CAISO, 2005; Kraftnät, 2006; Kiener, 2006; Elia, 2006; Rebours et al., 2007).

There seems to be no obvious answer, which is the most appropriate way to go as an apparent contradiction exists between efficiency and security. Shorter contract durations tend to foster efficiency through increasing the flexibility of the bidders and reducing the offer risk. On the other side, the critical issue of system security is raised by the TSOs and the bid sufficiency and investment incentives are questioned.

An increasing body of literature studies design issues of reserve capacity markets. One line of research investigates settlement rules (see Singh and Papalexopoulos, 1999; Kamat and Oren 2002). Others explore the issue of scoring the two-dimensional bids (see Bushnell and Oren, 1994; Chao and Wilson, 2002; Swider, 2007b). To our knowledge the question about the contract duration for primary and secondary reserve has not been specifically addressed so far. Büchner and Türkucar (2005) propose to increase the contract period to enhance the security of supply, but do not discuss any further implications. For tertiary or non-spinning reserves Crampton et al. (2005) argue in favour of extended contract periods as this would improve the investment incentive, while short-term markets "would not play an important role in efficient scheduling and dispatching of reserves." They exclude on-line reserve from this argumentation.

Indeed, this paper finds significant improvement potential in primary and secondary reserve dispatching and pricing as well as higher efficiency in the spot electricity market for shorter contract durations. Additionally, we show that the opportunity costs character of the reserve market implies sufficient incentives for supplying reserve capacity. Clear economical arguments and insights are developed while building on a theoretical framework by Just and Weber (2008) that models the basic economics of providing system reserve capacity. The paper focuses on primary and secondary reserve capacity. They are together referred to as online reserve capacity in the following.

The paper is organized as follows: In section 2, the market for reserve capacity in Germany is explained. The model of Just and Weber (2008) is summarized in section 3, including a discussion how the theoretical framework can be applied to other reserve qualities. In section 4 , the efficiency implications for different contract durations are investigated based on a specific data set describing roughly the German market. Section 5 discusses system security concerns for a more balanced perspective on the topic. Finally, the conclusions are drawn and implications for the market design are summarized.

\section{CURRENT MARKET DESIGN FOR SYSTEM RESERVE CAPACITY IN GERMANY}

For economical and technical reasons, three hierarchical levels of system reserve capacity exist in Germany and Continental Europe: primary, secondary and tertiary reserves (see UCTE, 2004 and ETSO, 2003).

Primary control activates the corresponding primary reserve capacity immediately to stabilize the system frequency in case of a disturbance. The full response is to be reached within 30 seconds. The activation is done automatically and decentrally through governor control by all generators that provide primary reserve capacity. Secondary reserves are activated by the centralized automatic generation control (AGC) to restore the system frequency and free the primary reserves. The activation starts also immediately after a disturbance and must reach full level within 5 minutes. The tertiary reserve capacity is used to restore und support the secondary reserves. The response time is typically slower than for secondary control. Tertiary reserves are activated manually via re-scheduling by the TSO and should be fully available 15 minutes after the activation.

Ex ante known fixed amounts of capacity are required for all three reserve types. The actual requested energy from the reserved capacity is uncertain. As a requirement of the response 
time, primary and secondary reserves need to be provided by online or spinning capacity ${ }^{5}$, whereas tertiary reserves do not necessarily.

After the liberalization of the German electricity market in 1998, the four TSOs procured the necessary reserve capacity via bilateral contracts mainly from their generation affiliates. Since 2001, the German TSOs have to use public auctions to reserve the capacity (see Regelleistung, 2009 and Swider, 2006 for details).

Separate auctions exist for each of the five distinguished products: primary, incremental and decremental secondary, incremental and decremental tertiary reserve capacity. The auctions used to be held in each of the four control zones separately. Until December 2007, primary and secondary reserve capacity had been procured half-yearly and partly in two time segments. ${ }^{6}$ The contracting periods have then been reduced to one month and also one common procurement auction is organized since December 2007. The distinction of time segments has been kept for secondary reserve only: peak (Mon-Fri: 8am-8pm) and off-peak (otherwise including public holidays).

Bids for primary reserve consist of a quantity and a reservation price. They are selected based on the reservation price and paid as bid. The actual use of the capacity is not rewarded separately as it is assumed that the incremental and decremental primary energy offset each other. For secondary reserve three bidding parts are required: a quantity, a reservation price for the capacity provision and an energy price for reserve capacity actually called. The offers are selected by the reservation price only and paid as bid. If needed, the selected capacities are called by the increasing merit order of the energy prices. Again, a pay-as-bid settlement is employed. The markets for tertiary reserve are very similar to secondary reserve, except that the auctions are held daily before the spot market with six time segments each of four consecutive hours.

All successfully selected offers have to be available during the whole contract period.

The German TSOs administrate these auctions for system reserve capacity and run them independent of all other energy transactions in the system. As a result the markets for energy and system reserve are only economically connected via the generators that can commit the very same MW of capacity only in either of the markets. Under this market design, the TSOs are not involved in the unit commitment and co-optimization decisions are in the hands of the generators.

\section{MARKET MODEL FOR ON-LINE RESERVE CAPACITY}

For every existing generation capacity, the "out-of-pocket" costs for reserving the capacity (keeping some share of it idle for eventual use) are virtually zero. All costs of building new generation capacity, which are often also called "capacity costs", are economically irrelevant for any further decision once the plant exists. They are sunk. ${ }^{7}$ Does this mean that reserve capacity should be offered for free?

For any profit-maximizing plant owner, it is rather a question of alternatives. If a profit can be earned while producing electricity and selling it into the spot market, keeping the capacity in reserve comes with the cost of not earning the profit in the spot market. Hence, the reservation

\footnotetext{
${ }^{5}$ As the response time of hydro storage power plants is much faster, they can provide secondary reserve even if they are not running.

${ }^{6}$ For primary reserve only the E.ON Netz control zone distinguished between peak and off-peak segments. However, all control zones used a peak/off-peak differentiation for secondary reserve (see Swider, 2004).

${ }^{7}$ This does not imply that those "capacity costs" have not to be re-captured (incl. adequate return on capital) during the life-time of the plant, as otherwise no one would invest into new capacity. We will briefly return to this issue later.
} 
of capacity might involve significant opportunity costs. The consideration of the individual plant owner facing different alternatives is the core of the fundamental reserve market model developed by Just and Weber (2008). At first, the focus is on incremental secondary reserve capacity. Later in this section, adaptations for the other reserve qualities are discussed.

\subsection{Modeling incremental secondary reserve capacity}

The pricing considerations for reserving capacity under equilibrium conditions are derived from the involved trade-off between two markets, assuming the existence of a secondary reserve power (SRP) and spot electricity market only. A plant owner is indifferent between offering the capacity share $k^{S R P}$ in either of the two markets, if he can expect the same profit in both markets: ${ }^{8}$

$$
E\left[\Pi_{S p o t}(x)\right]=E\left[\Pi_{S R P}(x)\right]
$$

with $E\left[\Pi_{\text {Spot }}(x)\right]$ the expected spot market profit of plant $x$ and $E\left[\Pi_{S R P}(x)\right]$ the expected secondary reserve market profit, each for capacity share $k^{S R P}$ over the contract duration period for secondary reserve. With the commitment to provide SRP, the plant looses its flexibility of backing down when the spot price is below its marginal generation costs due to the "mustrun" requirement. ${ }^{9}$ Expected additional must-run costs or negative profits are the price for this loss of flexibility. This applies only for the capacity share $k^{\mathrm{Min}}$; the minimum relative load level above which the plant can run stably. When these additional must-run costs are accounted for, the profit earned from the capacity share $1-k^{S R P}$ is irrelevant for this consideration. ${ }^{10}$

Assuming a net plant capacity of unity, the expected profit from providing SRP under a market design with two prices (a reservation price and an energy price for the actually used energy) and marginal pricing ${ }^{11}$ can be stated as

$$
E\left[\Pi_{S R P}(x)\right]=k^{S R P} R^{*}+E\left[\Pi_{\text {Act.Use }}(x)\right]-E\left[C_{\text {Running }}(x)\right]
$$

with $R^{*}$ the marginal reservation market price, $E\left[\Pi_{\text {Act.Use }}(x)\right]$ the expected profit from the actual use of SRP and $E\left[C_{\text {Running }}(x)\right]$ the expected additional cost incurred if the plant needs to be running over the contract period. In order to participate in the SRP market, the plant owner has to provide a reservation price bid. This reservation price bid $R(x)$ for plant $x$ is the result of the opportunity cost consideration of the alternative use and is derived by using equations (1) and (2) as follows

\footnotetext{
${ }^{8}$ Technically, generation plants can usually provide only a limited amount of reserve capacity due to the load adjustment speed within the required response time.

${ }^{9}$ As explained above, hydro storage plants have faster response times which allow providing secondary reserve without being on-line. The economic rationale to provide reserves is therefore different relative to thermal plants. In order to avoid a much higher level of complexity the model abstains from hydro storage plants. Later in the paper some implications of hydro storage plants are briefly discussed.

${ }^{10}$ Note in a simplification of reality, we assume no efficiency losses under part load and no additional wear and tear of the plant from frequently changing the load level through the calling of energy.

${ }^{11}$ Marginal remuneration does not correspond to the actual German market design. Under a pay-as-bid regime, bidding of marginal costs cannot be assumed. Rather, market participants will attempt to guess the marginal reservation price and align their bids accordingly. The bidding consideration for the energy bid is more complicated and analytically demanding. Therefore, pay-as-bid settlement is not retained further. An intuition that both settlement schemes result in similar market results under competitive conditions is given in Just and Weber (2008).
} 


$$
R(x)=\frac{E\left[\Pi_{\text {Spot }}(x)\right]+E\left[C_{\text {Running }}(x)\right]-E\left[\Pi_{\text {Act.Use }}(x)\right]}{k^{\text {SRP }}} .
$$

$R(x)$ is the minimum reservation price at which plant $x$ is willing to provide SRP. Only the marginal plant in the SRP market $x^{*}$ is indifferent between the two markets, i.e. $R\left(x^{*}\right)=R^{*}$. All other plants selected to provide SRP will earn a higher profit in the SRP market as their minimum reservation price $R(x)$ is smaller than the marginal price $R^{*}$. This implies that the plant owners have the incentive to offer the full available secondary reserve capacity share $k^{S R P}$.

Further assumptions and descriptions are necessary when moving from the individual consideration to an overall market equilibrium model.

To ensure competitive conditions, the supply side is assumed to consist of large number $x_{\max }$ of power plants with equal net capacity of unity, each belonging to a different risk-neutral owner. All plants have the same overall characteristics, except for different marginal generation costs, which are assumed constant over the considered bidding period. Without loss of generality, the power plants are ordered by increasing short-run marginal costs (SRMC). Thus, the variable $x$ designates the plant position within the merit order. $C(x)$ indicates the SRMC function of the market. All plants are supposed to have $100 \%$ availability during the bidding period.

The demand in the spot market is inelastic and over a certain period of time assumed to be a random variable with a density function $l(y)$, which covers all moments throughout the bidding period. Competitive conditions assure the bidding of marginal cost $C(x)$.

If bidding would occur in a spot-market-only world, the supply function for the spot market would equal the marginal cost function $C(x)$. However, the consideration of the additional SRP market changes two major aspects. First, capacity sold in the SRP market is no longer available for the spot market - it is effectively withheld. Second, plants providing SRP must run at least at the minimum capacity share $k^{\text {Min }}$ over the whole period considered. To assure this, rational bidders offer this capacity share $k^{\text {Min }}$ at a bid price of zero. The resulting spot supply curve is a transformed overall marginal cost function $C(x)$, which is partly shifted to the right and partly compressed. Thus, the average spot price depends on the plants selected for reserve provision, as we will see later.

The demand of incremental SRP capacity $Q^{S R P}$ that needs to be reserved is ex ante known and constant over the considered period. The actual amount $q$ to be called is ex ante unknown, but is assumed to follow a normal distribution $N\left(\mu, \sigma^{2}\right)$ denoted $f(q)$ as illustrated in Figure 1. For incremental secondary reserve only a positive demand is relevant.

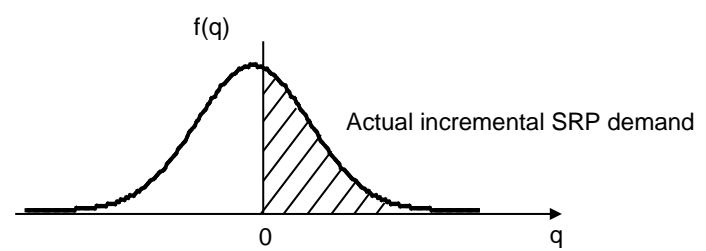

FIGURE 1: DENSITY FUNCTION OF THE ACTUAL INCREMENTAL SRP DEMAND

The market for SRP is held some time before the spot electricity market. In the market clearing process, the reserve capacity offers with the lowest reservation price bids are selected to fulfill the SRP demand $Q^{S R P}$ and are compensated by the marginal price $R^{*}$. The power plants selected to provide SRP can be defined by the following binary function

$$
S\left(x, R^{*}\right)= \begin{cases}1 & \forall R(x) \leq R^{*} \\ 0 & \forall R(x)>R^{*},\end{cases}
$$


The market clearing condition can then be formulated as

$$
k^{S R P} \int_{0}^{x_{\max }} S\left(y, R^{*}\right) d y=Q^{S R P} .
$$

The selected reserve capacity offers will be called for actual use according to their energy price bid, the lowest first. Again, the use will be compensated by the energy price bid of the marginally used capacity. In this setting, given the atomistic market structure, the plant owners will bid their marginal generation costs $C(x)$ as the energy price. ${ }^{12}$ Also for the reservation price, the marginal costs will be bid under prefect competition, yet including the opportunity costs for reserving the capacity.

Different contract durations in the SRP market go along with different spot demand distributions for the respective time horizon and imply different reservation prices due to changes in the expected profits in the spot market and in the must-run cost.

The minimal required reservation price can be determined for every plant in market equilibrium using the core equation (3). However, the result is not trivial as both, the expected spot market profit and the expected additional running costs depend on the expected spot prices over the contract period, thus on the transformed spot supply curve, which in turn depends on the selected "SRP plants" based on their reservation price bids. Also the expected profit from the actual use depends on the position within the energy price merit order and, thus, again on the other selected "SRP plants". The equilibrium reservation price problem turns out to be an implicitly defined integral equation system with binary variables as follows

$$
\begin{aligned}
R\left(x, R^{*}\right) & =\int_{x}^{x_{\max }}[C(y)-C(x)] l\left(m\left(y, R^{*}\right)\right) n\left(y, R^{*}\right) d y \\
& +\frac{k^{M i n}}{k^{S R P}} \int_{0}^{x}[C(x)-C(y)] l\left(m\left(y, R^{*}\right)\right) n\left(y, R^{*}\right) d y \\
& -\left\{\begin{array}{cc}
0 & \text { if } S\left(x, R^{*}\right)=0 \\
\int_{x}^{x_{\max }}[C(y)-C(x)] f\left(q\left(y, R^{*}\right)\right) p\left(y, R^{*}\right) d y & \text { if } S\left(x, R^{*}\right)=1
\end{array}\right.
\end{aligned}
$$

with

$$
\begin{aligned}
& n\left(x, R^{*}\right)= \begin{cases}\left\{\begin{array}{ll}
0 & \text { if } S\left(x+x_{\max }, R^{*}\right)=0 \\
k^{M i n} & \text { if } S\left(x+x_{\max }, R^{*}\right)=1
\end{array}\right\} & \forall-x_{\max } \leq x<0 \\
\left\{\begin{array}{ll}
1 & \text { if } S\left(x, R^{*}\right)=0 \\
1-k^{M i n}-k^{S R P} & \text { if } S\left(x, R^{*}\right)=1
\end{array}\right\} & \forall 0 \leq x \leq x_{\max }\end{cases} \\
& m\left(x, R^{*}\right)=\int_{-x_{\max }}^{x} n\left(y, R^{*}\right) d y,
\end{aligned}
$$

\footnotetext{
12 The selection by the reservation price only and the marginal price remuneration ensures that the bidders have the incentive to reveal their true costs under competitive conditions. See Chao and Wilson (2002) for a rigorous analytical treatment of this argument.
} 


$$
\begin{aligned}
& p\left(y, R^{*}\right)=\left\{\begin{array}{cc}
0 & \text { if } S\left(y, R^{*}\right)=0 \\
k^{S R P} & \text { if } S\left(y, R^{*}\right)=1
\end{array}\right. \text {, and } \\
& q\left(x, R^{*}\right)=\int_{0}^{x} p\left(y, R^{*}\right) d y .
\end{aligned}
$$

Equation (6) states the minimum required reservation price for plant $\mathrm{x}$ in market equilibrium consisting of the three parts: the expected opportunity cost from not offering the capacity in the spot market plus the expected additional must-run cost minus the expected profit from the actual use the reserve capacity. ${ }^{13}$

In the first term, the expected spot profit is determined as the probability-weighted profit margin earned when the spot price is higher than the variable generation cost $C(x)$ of plant $x$. Thereby the spot price is set by the variable generation cost $C(y)$ of non-must-run capacity to the right of plant $x$ in the transformed spot supply curve. The second term adds the probability-weighted loss incurred with must-run capacity share $k^{M i n}$ if the spot price in below $C(x)$. The third term subtracts the probability-weighted profit margin earned if the energy price $C(y)$ is greater than the variable generation cost $C(x)$ in case plant $x$ is selected to provide reserve capacity. Otherwise no profit is earned from the actual use of reserve capacity.

The equations (7) and (8) are descriptions of the transformed spot market merit order. $n\left(x, R^{*}\right)$ determines the capacity share available at the original merit order rank $\mathrm{x}$ with an extension to incorporate the must-run capacity. $m\left(x, R^{*}\right)$ states the position of the non-must-run capacity of plant $x$ along the transformed spot supply curve. Equations (9) and (10) are the equivalent descriptions of the resulting energy price merit order for the capacity that has been selected to provide SRP.

As it is more accessible, the results of the model are illustrated in Figure 2 for an exemplary set of parameters (actually case 1 of the simulation that follows in section 4). Nonetheless, the shape of the reservation price function is rather general. The required reservation price $R\left(x, R^{*}\right)$ indicated by the grey/black line is specified by the three components: expected opportunity costs from foregone spot profits (dark area) plus the expected additional running cost (light area) minus the expected profit from actual use of SRP (area below the abscissa). The expected spot profits are decreasing for power plants with increasing marginal costs as the generation of electricity gets more expensive and the probability of delivery decreases. Obviously, the plants with the lowest marginal costs earn the highest profits and thus have the highest opportunity costs. The expected additional costs from running the plant are increasing. Due to the higher marginal generation costs, keeping the plant running gets more and more expensive. These both are the main determinants of the reservation price. They overlap along the section between the minimum and maximum spot demand, e.g. along the strict positive spot demand density (indicted by the grey line in the lower part of Figure 2).

The expected profit from actual use is of minor importance in absolute terms, but might have a distinctive influence on the identification of the "SRP plants". This influence is the greater, the flatter the trough around its minimum. The location of the trough and, thus, the "SRP plants" are essentially determined by the spot demand (distribution). It generally holds that the closer a plant is to the marginal spot plant, the smaller are the forgone spot profits and/or the additional costs of a running plant, thus resulting in relatively low reservation prices. The plants that provide SRP in the equilibrium state have on average the smaller opportunity plus

\footnotetext{
${ }^{13}$ The following description of the formulas focuses more on a general understanding than an exact explanation. This can be found in Just and Weber (2008) including the derivation of the formulas.
} 
must-run costs over the contract duration. They are marked black and the "non-SRP plants" grey along the required reservation price function $R\left(x, R^{*}\right)$.

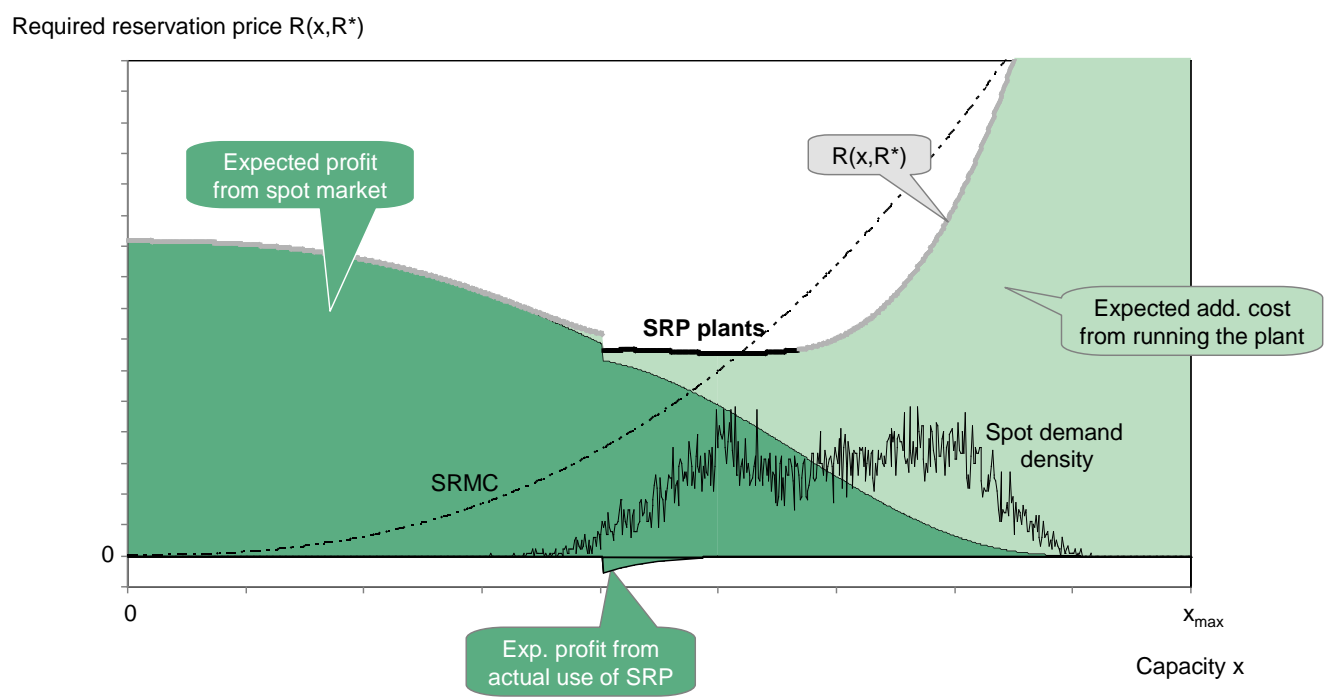

FIGURE 2: REQUIRED RESERVATION PRICE FUNCTION AND ITS COMPONENTS

Besides specifying the reservation price bids and the most economical "SRP plants", the equilibrium model determines the SRP energy price bids as the marginal generation costs of those plants and the expected average spot price over the considered period.

To shed more light into the market dynamics, four simple spot demand cases are considered and the corresponding required reservation price functions $R\left(x, R^{*}\right)$ are depicted in Figure 3. Thereby, cases (a) to (c) indicate three distinct periods with a well-defined spot demand each. In contrast to Figure 2, here only the reservation price function $R\left(x, R^{*}\right)$ is shown - basically a V-shaped line with a kink at the start of the section with the "SRP plants". With a constant and known spot demand in each of the periods, the marginal spot market plant would have no opportunity and no must-run costs, and thus essentially no "reservation costs". Incremental secondary reserve is most economically provided by the plants around this marginal spot plant. They face either opportunity or must-run costs - resulting in the distinct V-shape of $R\left(x, R^{*}\right)$. Note that SRP is provided partially by extra-marginal plants. They only bid the mustrun share in the spot market in order to participate in the SRP market. Due to the convex SRMC, the marginal reservation prices increase with higher spot demand, e.g. $R_{(a)}^{*}<R_{(b)}^{*}<R^{*}{ }_{(c)}$. Each demand case induces a different set of optimal SRP plants (the black marked troughs).

Case (d) is a combination of the other three cases. It can be either thought of as a period comprising the three sub-periods (a) to (c) or a period with uncertain spot demand with the three possible realizations (a) to (c) each with a probability of $1 / 3$. As a consequence, the consideration of each plant changes as a multitude of plants now face both expected opportunity and must-run costs for the mix of different system conditions (the overlapping opportunity and must-run cost functions are specifically depicted in Figure 3) ${ }^{14}$ This results in higher marginal reservation prices $R_{(d)}^{*}>\left(R_{(a)}^{*}+R_{(b)}^{*}+R_{(c)}^{*}\right) / 3$. Another important point is that the most economical SRP plants are further to the left compared to the average case (b). This implies that relatively more capacity is effectively withheld from the spot market than on

\footnotetext{
${ }^{14}$ A direct graphical summation of the cases (a) to (c) in Figure 3 is not possible as the SRP plants shift. This results in a change of the transformed spot supply curve and subsequently also of the expected opportunity and must-run costs.
} 
average in the three separate demand cases. This means that the expected spot price is higher in case (d) than the average spot price for demand periods (a) to (c). The reserve market has a direct feedback on the spot market.

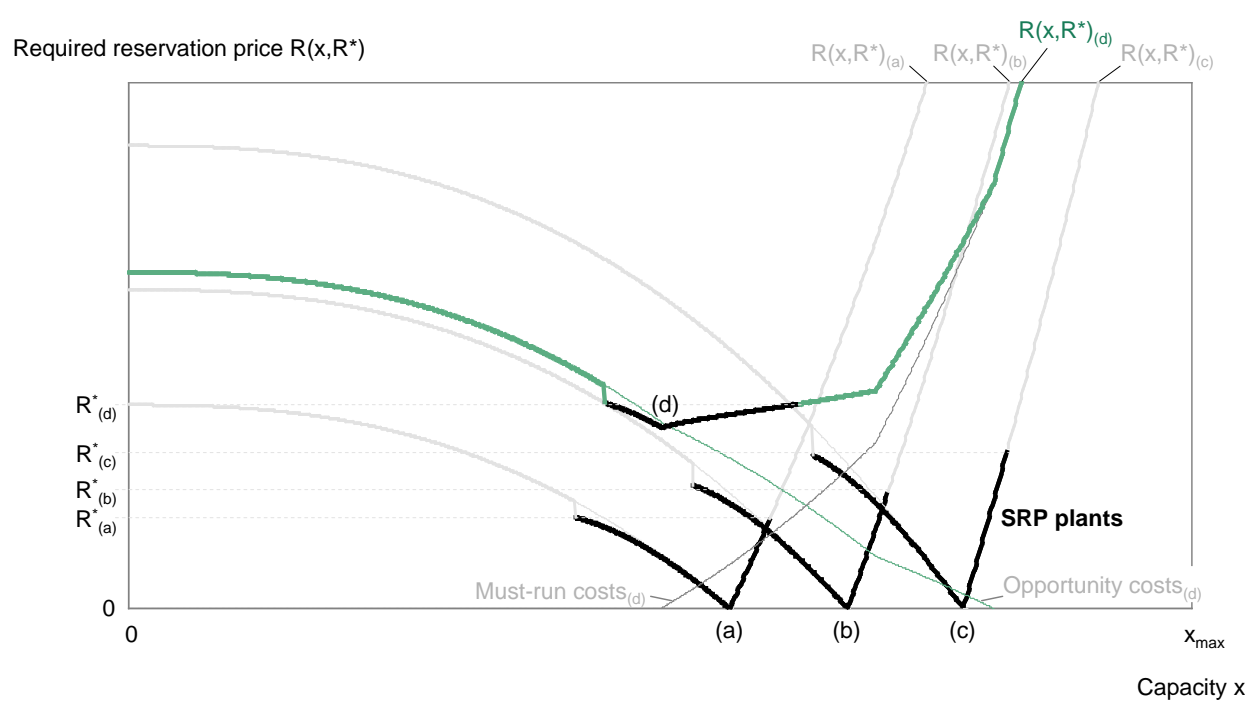

FIGURE 3: REQUIRED RESERVATION PRICE FUNCTION FOR DIFFERENT SPOT DEMAND CASES

The main results from this simplified model can be summarized as follows:

- The marginal reservation market price is mainly driven by the steepness of the SRMC curve around the section that is actually price-setting in the spot market. The steeper the SRMC, the steeper are the expected spot profit and the expected must-run cost functions. As SRP has to be provided from a multitude of plants, the relatively higher opportunity and must-run costs of the marginal reserve plant translate directly into higher required reservation prices. This effect can be seen is Figure 3. Due to the convexity of the SRMC, the relevant SRMC-section is relatively steeper for a higher demand case and so is the marginal reservation price. The absolute level of the marginal generation costs influences only the energy prices for used capacity.

- The reservation prices are expected to be higher in periods with higher spot demand, given the general convexity of the SRMC in the market.

- The smaller the average capacity share $k^{S R P}$, the more plants or net installed capacity is necessary to provide the required reserve. As a result the reservation prices are higher.

- Less intuitive, the shape of the marginal cost curve has almost no influence on which plants can provide SRP most effectively. They are essentially determined by the distribution of the spot demand and the plant parameter $k^{S R P}$ and $k^{M i n}$. Simply speaking, secondary reserve is provided most economically by the plants close to the expected marginal spot market plants. At different times (of the day) different plants are more suitable for SRP provision.

- The lower the uncertainty/variation of the spot demand, the lower are the reservation prices and the more efficient is the reserve capacity dispatch resulting also in lower average spot prices. This property has an important implication for the definition of contract durations in the reserve market and is detailed in section 4. 


\subsection{Application of the model to other reserve qualities}

With some minor adaptations, the same model can be used for primary reserve power (PRP) as well. As the bids for primary reserve consist of a reservation price only, the expected profit from actual use can be omitted. Adding to this fact, the amount of upward and downward regulation is basically the same, resulting in a balance of additional costs for increased generation and avoided costs from reduced generation. Another difference is that a plant offering primary reserve has to provide footroom for downward regulation, which increases the effective minimum must-run capacity share by the reserve capacity share $k^{P R P}$. Thus, $k_{\text {eff }}^{\text {Min }}=k^{M i n}+k^{P R P}$. In general, the reserve capacity share $k^{P R P}$ per plant is lower than $k^{S R P}$ due to the faster required response time. The overall results evolve very similarly to the ones for incremental secondary reserve and so does the shape of required reservation price function.

For incremental tertiary reserve, this theoretical model is only partly applicable since the technical requirements differ. Tertiary reserve can either be provided by partly unloaded spinning generation capacity or by non-spinning capacity that can be brought on-line within 15 minutes. For all plants that cannot ramp up fast enough, the condition are basically the same as for secondary reserve.

The fast-ramping plants (e.g. gas turbines) do obviously not face the must-run costs, but incur start-up costs when being off-line and called. Still, they might forego possible profits from the spot market. The expected start-up costs are rationally included in the energy price bid. This complicates the formulation of the expected profit from the actual use significantly. Partly because the start-up costs are not directly related to the amount of energy called and partly due to reversals in the energy price merit order. The model presented before is not readily applicable to tertiary reserve. The reservation prices are expected to be virtually zero as long as enough reserve capacity can be provided by fast-ramping capacity which has no chance to provide spot electricity. The higher the probability that this capacity could generate spot electricity, the higher is the required reservation price. In extreme cases, the provision of tertiary reserve can get very expensive.

The general logic of providing decremental secondary and tertiary reserve is basically the same. For both, the ability to reduce the plant's load level on request of the TSOs is necessary. Thus, decremental reserve can only be provided by plants which run above their minimum required load level $k^{\text {Min }}$. More precisely, those plants must run at least at the effective capacity share $k_{\text {eff }}^{\text {Min }}=k^{\text {Min }}+k^{\text {Dec }}$ with $k^{\text {Dec }}$ being the capacity share offered as decremental reserve. This might result in must-run cost or costs for uneconomic dispatch if the spot price is below the marginal generation costs.

When the decremental reserve is called and the load is reduced, marginal generation costs are avoided. Still, the plant earns the revenue from the contracted energy sold. Under competitive conditions and marginal settlement, the avoided marginal costs are rationally bid as the energy price. The bids are called in the reverse order, the highest price first, and the TSOs are paid by the plant owners. As in the case of incremental energy, this provides the opportunity to earn a profit from the actual use; the difference between the own avoided costs and the lower bid price of the marginally called energy reduction.

Basically, it should be expected that the reservation prices are virtually zero when enough plants run at full-load. A significant positive reservation price is anticipated only in off-peak times with very low demand. The price formation depends crucially on the exact status of the plants being on-line during those times. This would require a more detailed modeling approach than captured in the present model. The energy price bids should be higher in times of higher demand. The average spot price is expected to be largely unaffected. 


\section{THE QUESTION OF CONTRACT DURATION - THE EFFICIENCY PERSPECTIVE}

One of the main arguments why market-based solutions are introduced is the promotion of efficiency - meaning lower prices and a better use of the employed resources. Proper market designs should foster efficiency - and so should the appropriate definition of the contract duration in reserve capacity markets.

When considering the issue of different contract durations for on-line reserve capacity, the crucial question is the level of heterogeneity and uncertainty associated with the contract duration and the resulting reserve bids. By heterogeneity, the variety of system conditions is understood, which is an evident feature of the electricity industry and which manifests itself also in a high price volatility. The marginal plant producing electricity changes frequently and over a broad range of the merit order. This is mainly caused by shifting electricity demand patterns (e.g. daily, weekly and yearly cycles), which are more or less predictable. Consequently, the heterogeneity of marginal plants with which the bidders in the secondary reserve are confronted with, is strongly dependent on the contract duration.

Some of the lessons from the reserve market model are that on-line reserve is provided most economically from plants close to the marginal spot plant and that lower uncertainty/variation of the spot demand yield more efficient market results. An appropriate definition of the reserve contract duration has the same efficiency impact as a temporary specialization or division of labor. Different plants are most suitable to provide reserve at different times with heterogeneous momentary system conditions. This effect of temporal adaptation is illustrated by a simulation of different contract durations based on a data set that roughly fits the German market (see Appendix). Subsequently, the relevance of the model simplifications is discussed followed by an investigation of the role of price uncertainty, flexibility and transaction costs.

\subsection{Adaptation to varying system conditions}

The temporal adaptation effect is exemplified by five cases of different contract durations, each characterized by the according (empirical) spot demand distributions:

1. One-year period without any distinction between peak and off-peak hours.

2. Half-year periods with a distinction between peak hours (weekdays 8am-8pm) and off-peak hours (others incl. public holidays), which corresponds to the scheme used till November 2007.

3. Monthly periods with peak/off-peak, corresponding to the current scheme for secondary reserves.

4. Four-hour periods as they are used in the tertiary reserve auctions.

5. Hourly periods as used in the spot market.

The results of the equilibrium model are depicted in Figure 4. The prices are the yearly averages. It becomes evident that the less variation is involved in the contract period, the lower the average market reservation prices are. As a matter of fact, providing reserve capacity from a plant for a period with a large variety of spot market prices (i.e. varying spot demand) involves higher opportunity costs as well as higher additional running costs compared to multiple sub-periods each with a smaller variety of spot prices, in which different "more specialized" plants could provide the necessary reserve capacity more efficiently. Since the plants close to the marginal plant in the spot market can provide reserve capacity less costly, shorter contract durations with less variation allow less costly assignments of reserve capacity. The resulting more efficient dispatch of the capacity between the two markets leads also to a lower average spot market price. Less capacity is effectively 
withheld from the spot market by the reserve capacity market. ${ }^{15}$ This effect, that the reserve capacity plants are on average further right in the merit order, results however also in higher average energy prices of the effectively called reserve capacity. Yet these increasing energy prices are by far overcompensated by the reduction in average spot and market reservation price. The increased reserve energy prices reduce the overall savings only by about $2 \%$. Even a higher amount of reserves that is actually called upon does not have a material impact.

The overall effect clearly indicates that wise product definitions in the secondary reserve capacity market lead to more efficient results in both markets.

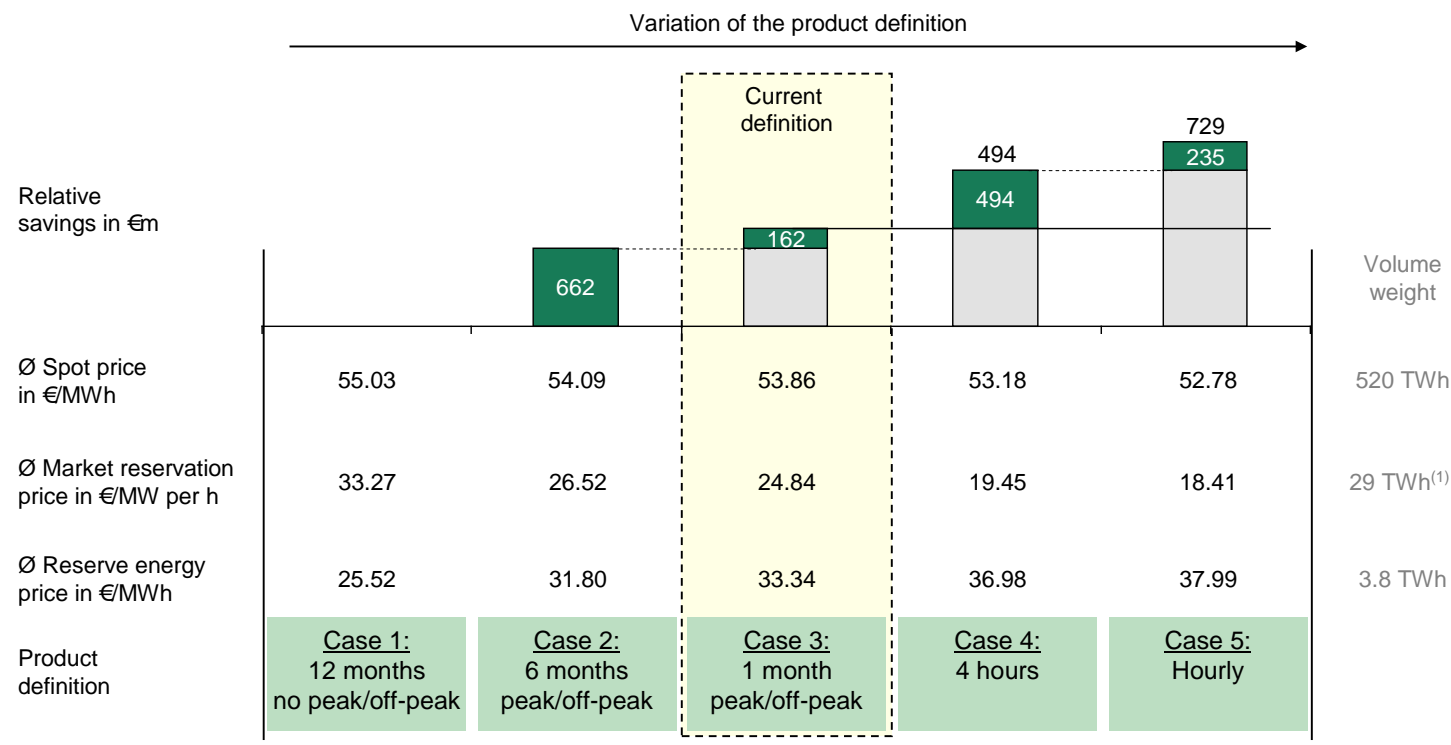

(1) Equivalent of 3,300 MW during 8.760 hours

FIGURE 4: RESULTS OF THE SIMULATION FOR SECONDARY RESERVE CAPACITY

The former and current product definitions of secondary reserve (case 2/3) were clearly chosen with the objective in mind to cluster periods with similar market conditions, i.e. similar dispatching pattern. The significant relative savings of about $€ 662 / 824 \mathrm{~m}$ underline that these are reasonable definitions compared to yearly contract durations (case 1). However, the theoretical calculations show that the current monthly definition (case 3) is only about half the way of the possible relative savings to be achieved by hourly auctions (case 5).

The effect on the average spot price is relatively small, but the leverage of the large spot electricity volume makes it economically very meaningful. About $75 \%$ of the relative savings result from lower average spot prices. In fact, the potential savings in the reserve market reduce the overall costs in the reserve market from about $€ 720 \mathrm{~m}$ with the current specification to $€ 534 \mathrm{~m}$ in case 5 (hourly SRP products). These savings of less than $€ 200 \mathrm{~m}$ might seem of limited importance. Yet they are complemented by reductions in the spot market price worth $€ 562 \mathrm{~m}$, i.e. more than the total direct cost of the secondary reserves.

All resulting savings can be either attributed to reduced marginal generation cost due to a more economic dispatch of the generation capacity or reduced profits of the plant owners (see Figure 5). The first account for about $30 \%$ of the savings on average and are essentially a gain in social welfare.

\footnotetext{
${ }^{15}$ The relative shift of the SRP plants and thus the degree of effective withholding of capacity from the spot market depends on the relative steepness of the expected opportunity and must-run cost function to each other. The relative steepness of the expected spot profit and additional running cost functions essentially depends on the relationship between $k^{M i n}$ and $k^{S R P}$. The SRP plants shift to the right for $k^{M i n}>k^{S R P}$ (the expected must-run cost function rises faster than the opportunity costs function) when the spot demand variation decreases (see Just and Weber (2008) for a detailed discussion of this property).
} 


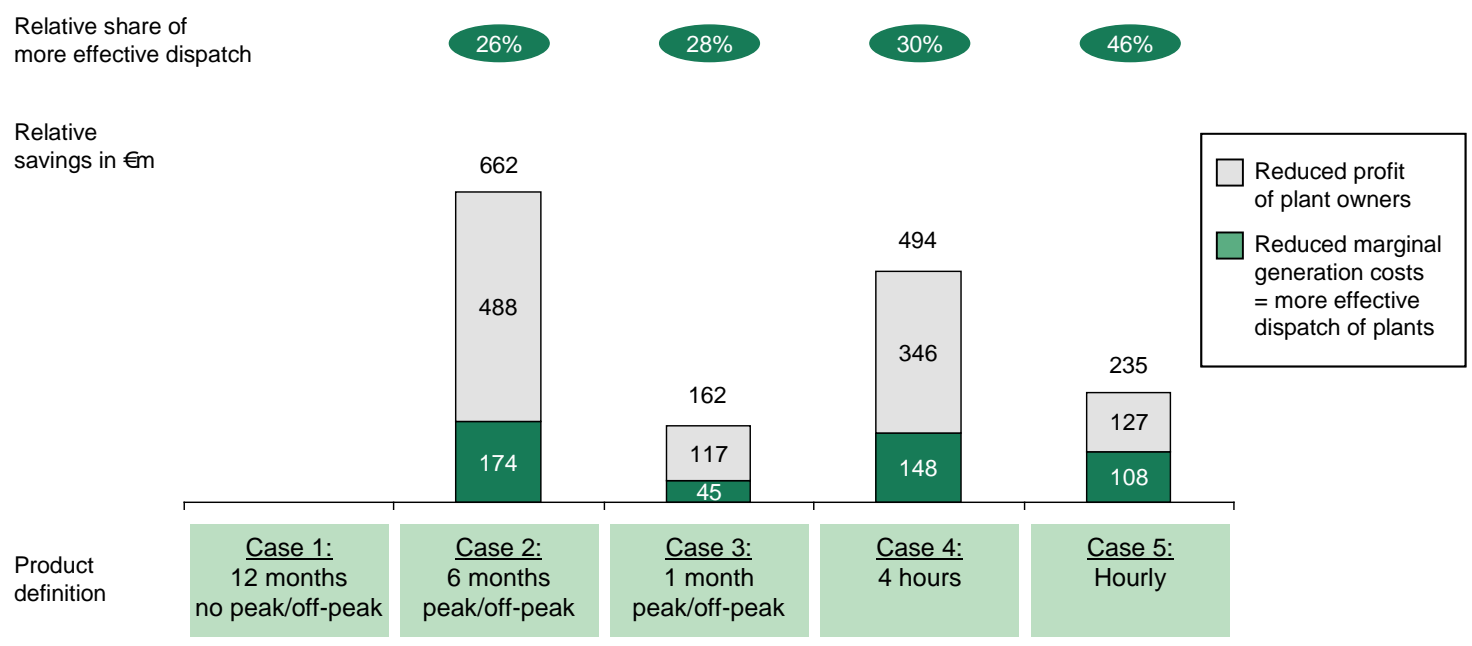

FIGURE 5: SOURCES OF RELATIVE SAVINGS FOR SECONDARY RESERVE CAPACITY

Very similar results are obtained for primary reserve (see Figure 6). This is to be expected as the basic market logic is the same. While the reduction from six to one month gives the plant owners more flexibility for planned outages, the impact in terms of a more efficient dispatch is small. The current definition of the contract duration (case 3a: monthly periods without peak/off-peak) appears to be even less efficient than the former partly used definition of 6 month with a distinction between peak and off-peak (case 2). It thus is rather questionable that the current definition does not contain those two separate time segments. By applying shorter contract durations the largest share of expected efficiency savings are still to be reaped. As before, hourly contract duration is the most preferable option from an efficiency perspective. Of the theoretical savings, again, about $30 \%$ can be attributed to more economic dispatch and avoided marginal generation cost.

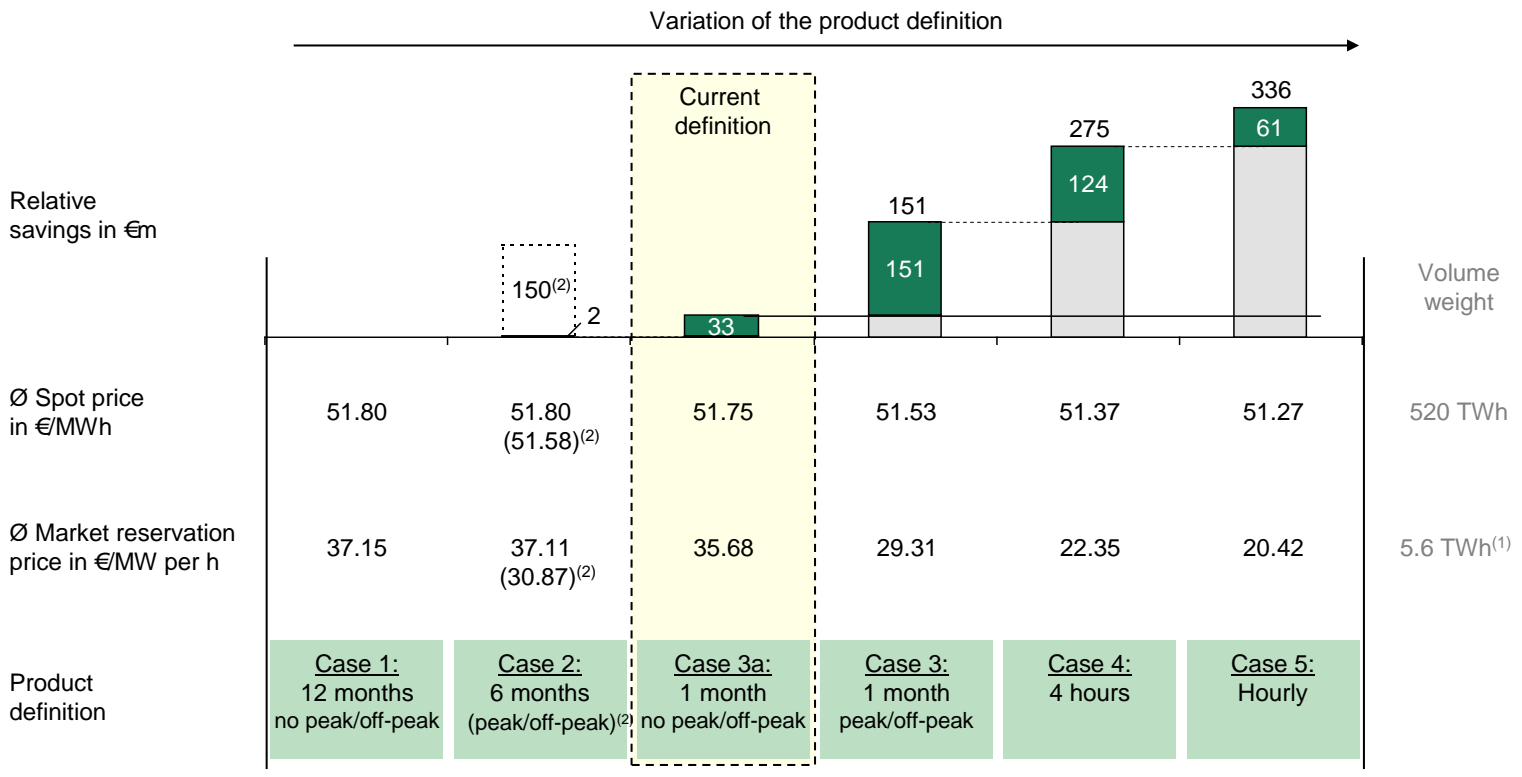

$\begin{array}{lll}\text { (1) Equivalent of } 660 \mathrm{MW} \text { during } 8.760 \text { hours } & \text { (2) A distinction similar to peak/off-peak was employed only partly before }\end{array}$ 
The relative savings for the simulations are indicative only, due to some simplifying assumptions. The individual numbers obtained should therefore be interpreted with care. But the fundamental logic for offering reserve capacity and the effect of a more efficient dispatch through shorter contract durations is rather general as will be argued in the next section.

\subsection{Relevance of model simplifications}

In reality, not all plants are technically able to provide PRP/SRP, but the large majority in the relevant part of the merit order is and could obtain the necessary pre-qualification, if they have not yet got it. The plant parameters $k^{S R P}$ and $k^{M i n}$ are not the same for all plants. Yet the general trade-off is still the same for each individual plant. Covering larger variations of market conditions within the same contract comes in any case with larger opportunity and additional "must-run" costs. As long as $k^{M i n}>k^{S R P}$ and $k^{M i n}>k^{P R P}$ is generally valid - which is practically the case - a higher spot demand variation leads to an increased effective withholding of capacity from the spot market and thus to higher average spot market prices.

The market model does not explicitly consider further costs caused by efficiency losses under part load or additional wear and tear through frequent load level changes. Those effects are at least comparable for similar classes of plants and thus add similar costs components. They hardly marginalize the effect of the discussed components of the reservation price.

Non-convexities such as the part load generation of lignite and coal plants during night times are not accounted for in the model above. For such cases the opportunity costs are negligible and the must-run costs are incurred anyway. Hence, the required reservation prices are virtually zero. This has a dampening effect on the average reservation prices. The logic in the remaining hours is unchanged. As the dispatching conditions vary significantly also during off-peak hours (even more than during peak hours), the "specialization" effect is still in place and expected to be significant.

Secondary reserve also can be supplied from pumped storage plants. ${ }^{16}$ They have no expected must-run cost, but the opportunity costs might be extremely high due to the limited water storage capacity and inter-temporal optimization opportunities. As a result, they might be an advantageous alternative during a few hours. The main implications and logic of the model are not expected to change as long as reserve is also provided by some thermal plants. Again, the level of reservation prices and potential savings might change slightly, but the basic effect from eliminating variation through appropriate contract definition remains the same.

Another deviation from reality is that the applied reserve market equilibrium model is based on uniform instead of pay-as-bid pricing. Under perfect competition and similar assumptions as used in this paper, Just and Weber (2008) argue at both pricing schemes might lead to the same results. In general, this question is widely discussed and largely ambiguous in the economic literature for less complex one-price electricity auctions (see Fabra et al (2006) and Federico and Rahman (2003) for theoretical discussions under various assumptions). Also experimental simulations reach different conclusions. Rassenti et al. (2003), Bower and Bunn (2001) and Mount et al. (2002) find that pay-as-bid pricing leads to higher average prices. Opposite results are obtained by Weidlich and Veit (2006) in an agent-based study that includes a two-price reserve capacity market. This underpins that the results are not clear and depend on specific assumptions and circumstances. However, the potentially achievable efficiency gains described in this paper persist independently of the actual bidding behavior.

Finally the supply structure in Germany does not correspond to textbook models of perfect competition, given that four companies control about $70-80 \%$ of the generation capacity. Combined with the fact that reserve capacities tendered in the auctions are not assigned to

\footnotetext{
${ }^{16}$ The installed hydro storage capacity with natural inflow is almost negligible in Germany. The majority of hydro storage consists of pumped storage capacity.
} 
individual plants, the large portfolio companies can reap a significant part of the saving effects. However, as the portfolios are limited they can not pocket the effect fully. ${ }^{17}$ An important direct implication of this is that longer contract periods favor companies with large flexible portfolios over companies with small portfolios. For them, the missing flexibility implies on average higher relative reservation prices and disadvantages in the auctions (with the potential effect of market deterrence). This will clearly result in sub-optimal market results.

\subsection{Price uncertainty and financial risk implications}

The choice of the reserve contract duration has risk implications. Under longer contract durations the reservation price is less volatile than under short contract durations. Hence, at first sight, longer contract durations seem to be advantageous from a risk mitigation perspective - for the generators as well as for the TSOs.

Risk-averse generators are generally interested in locking-in expected profits beforehand and in reducing the exposure to price uncertainty. Practically, derivative markets for generated electricity (forwards, futures, options and swaps) offer much better hedging opportunities against price volatility. First, generators can engage in derivative contracts longer time in advance with sufficient market liquidity compared to semi-annual or annual reserve contracts. Second, those markets offer much more flexibility to engage in different contracts that suit best the company's individual risk profile. Third and most importantly, such contracts can be unwound at market value if necessary as they are traded continuously.

Generators can hedge their output/capacity long-term and still engage in the reserve capacity market. Even if the full output is sold physically forward, the generator can relatively easily buy back electricity short-term (e.g. in the spot market) and offer the freed-up capacity in the reserve capacity market. ${ }^{18}$ The opportunity cost logic of reserve capacity pricing offers enough incentives to conduct such a "spot-reserve swap" (see section 5 for a more detailed discussion of the incentive).

The higher volatility has also implications for the TSOs procuring the reserve capacity. For the TSOs only the reservation price payment is of interest. ${ }^{19}$ They are reimbursed through the regulated transmission tariffs, which are set usually before the reserve auctions take place. Whether the TSOs can recover all the actual reserve capacity costs is a regulatory question and not of foremost interest at this point. ${ }^{20}$ Hence, let us assume that the regulation allows recovering the total actual reserve capacity costs. Then the contract duration only has

\footnotetext{
17 The four large German generators have a broad range of generation assets each. However, RWE and Vattenfall Europe have disproportional high share of base load plants (mainly lignite), whereas E.ON and EnBW are relatively stronger in mid load generation. Vattenfall Europe can serve peak load mainly from pump storage plants, and the other three rely predominately on quick to start-up gas and oil capacity for peak load generation. As a result they are suited differently to provide online reserve capacity and can reap the portfolio savings to a different extent.

${ }^{18}$ A temporal alignment of the reserve capacity markets with other electricity markets is necessary to reduce the risk of such transactions.

${ }^{19}$ In Germany, the actual reserve energy payments are re-charged immediately to the market participants responsible for the imbalance - the load serving entities or balance responsible parties contributing to the imbalance. Those money transfers are irrelevant for the TSOs.

20 The current yard-stick regulation in Germany treats costs for ancillary services (e.g. reservation price payments for reserve capacity) as permanently non-influenceable and allows basically a pass-through. Any deviations between planned and actual pass-through costs are settled via multi-year settlement accounts.

Further developments of the yard-stick regulation could create even incentives for more efficient procurement of ancillary services. Even if the TSOs cannot influence the prices themselves in the auctions, they have an influence on the design of those auctions and thereby indirectly on the associated (,non-influenceable“) costs.
} 
implications for the cash management of the TSOs. Shorter contract durations with a higher volatility in reserve capacity payments cause a higher degree of unpredictability of the payments leading to higher working capital requirements or more expensive flexible credit lines. However, a large part is predictable as daily and weekly demand pattern are wellknown. Yet these uncertainty-related costs for the TSOs are expected to be insignificant compared to the efficiency effects of shorter contract durations.

\subsection{Flexibility and outage uncertainty}

The commitment of providing reserve capacity reduces the flexibility of a plant owner. Failures and sudden outages can just happen, independently of the contract duration. But outages are not a one moment event and they occur usually over some period of time. Thus, shorter contract durations give the plant owner a higher flexibility to deal with it. Staying away from the reserve market, if the capacity is not available, is certainly less expensive than any replacement cost or penalty otherwise incurred under a long-term commitment. Higher flexibility is also convenient for scheduled outages. Shorter contract durations imply lower risk costs for non-availability or non-performance especially for small generation companies.

\subsection{Transaction costs}

The shorter the contract periods, the larger is the number of auctions and the higher are the transaction costs. With the appropriate automated systems in place on the system operator side, the additional costs are limited and certainly lower than the expected efficiency savings. ${ }^{21}$ The German TSOs have already a system that is used for daily auctions of tertiary reserve. For the generators on the other hand, handling reserve capacity is more or less a byproduct of the on-going dispatch optimization, including the short-term assignment of reserve capacity to individual plants which is done today. Closer proximity to delivery reduces also the complexity in bidding in the reserve markets as the market conditions are more evident. The increase in transaction costs is likely to be negligible or relatively insignificant. This may be illustrated through a simple estimation: Given the systems already in place, transaction costs comprise mainly personnel costs for additional coordination. A conservative estimation of the costs would include 1-2 persons for the system operators together and 0.5-1 person per bidding generating company, which are basically 5 today and maybe as much as 10 in the future. Assuming full personnel costs of $€ 100,000 /$ person, the generously estimated additional transaction costs are most likely less than $€ 1.5 \mathrm{~m}$.

\section{THE QUESTION OF CONTRACT DURATION - THE SECURITY PERSPECTIVE}

Ensuring system security is the reason for the existence and necessity of reserve capacity in the first place. Therefore, the provision of sufficient reliable reserve capacity is paramount. ${ }^{22}$ Sometimes it is argued in favor of longer contract periods for primary and secondary reserve as this would improve the overall system reliability while reducing the risk that reserve capacity is not available due to a lack of offers (see Büchner and Türkucar, 2005). The TSOs raised similar concerns as well as technical requirements in the process handling of reserve capacity (see BNetzA, 2007). Those concerns will be explored further in the following.

\footnotetext{
${ }^{21}$ This includes the process of connecting the plant into the control loop while re-programming the AGC. It is discussed more thoroughly in the next section as it is also a cause of security concerns.

${ }^{22}$ Whether the requested amount of reserve capacity by the TSOs is sufficient or even excessive is a completely separate question and is not subject of this paper. The respective demand is taken as given.
} 


\subsection{Concerns about bid insufficiency}

The nature of the reserve capacity market and its implied opportunity costs provide always an incentive to offer capacity. At the time of the bidding the complete expectations about the earning potential in alternative markets and all related costs (including bidding and risk costs as well costs resulting from part load inefficiencies and additional wear and tear) should be rationally considered in the required reservation price. At this price, the bidder is indifferent. Depending on the remuneration scheme and the degree of competitive pressure, the capacity is offered at the required reservation price or with a mark-up, but never below. When the offer curve is increasing, the successful offers get paid at par or above their indifference prices under a marginal pricing scheme. Mark-ups are rationally offered with pay-as-bid pricing up to the price of the marginal bid. The market ensures that reserve capacity earns at least as much as it would be expected to earn with any other alternative, e.g. in the spot market. ${ }^{23}$ The opportunity cost logic provides a structural excess profit in the reserve capacity markets even under competitive conditions. Generally, there is an abundance of capacity which could be offered as primary and secondary reserve. It is only a matter of the price attainable in the bidding procedure, yet this will not be limited since the TSOs act as price-inelastic buyers. ${ }^{24}$ Even if the expected probability of a bid being successful is regarded low, the almost negligible short-term bidding costs make an offering sensible yet. Hence, there should be enough economic incentives for offering reserve capacity.

The only instances in which the incentive mechanism may break down are if the reserve capacity market is held after all other electricity markets (then the above described swap is not possible anymore) or when there is an overall capacity shortage (available capacity smaller than load plus reserve provision). In that case, even if enough capacity is allocated to serve the reserve capacity demand, the resulting imbalance may be greater than the reserved capacity. But in that case the question is rather whether the spot market ensures sufficient investment in necessary capacity, a topic which has been widely discussed in literature (e.g. see Joskow and Tirole, 2007), especially for the case of energy-only spot markets like in Germany. Increasing contract duration in the reserve market will hardly help improving the situation, since the reserve market will anyhow attract sufficient bids given the interconnection between the two markets and the excess profits for inframarginal on-line reserve plants.

Given the achievable excess profits, there are enough long-term incentives for new and existing plants to be equipped for primary and secondary reserve provision. The majority of plants can theoretically provide PRP/SRP. ${ }^{25}$ Thus, in all moments there is vast excess supply of potential reserve capacity (plants that fulfill the response requirements once they are online). This potential installed reserve capacity must be pre-qualified and connected to the AGC in order to participate in the reserve markets. If the economic incentives to do so are considered as being insufficient, the pre-qualification could be established as a mandatory requirement for the initial connection to the grid of new plants.

After a possible reduction of the contract duration in the future, there might initially be a lack of trust by the TSO/ISOs that the market mechanism is fully understood and the higher profit opportunities are utilized. However, evidence from the daily German market for incremental tertiary reserve (with a similar incentive mechanism, but a less evident stimulus for long-term

\footnotetext{
${ }^{23}$ The additional profit can be seen in Figure 3 as the triangle between the required reservation price (black line) and the corresponding market reservation price (dotted line). This abnormal profit tends to be larger for shorter contract durations, increasing the incentive to offer reserve capacity in short-term markets.

${ }^{24}$ Even for plant owners who sold their full output already in the physical forward market a "spot-reserve swap" (buying output/capacity back in the spot or other forward market and offer the freed-up capacity as reserve) is still a profitable option. Such a swap is equivalent to a change in planned dispatch for owners of plant portfolios.

${ }^{25}$ As a technical and legal requirement in Germany, all plants with a capacity >100MW must be able to provide primary control.
} 
investments) does not indicate problems of offer insufficiency. During 2007, the excess supply in the auctions was at least $19 \%$ and on average about $57 \%$. Also in jurisdictions with short-term markets for primary, secondary or comparable reserves, attracting enough offers seems not to be an issue. ${ }^{26}$

The risk that actually called reserve capacity is not available is basically independent from the definition of the reservation periods. It might even be that near-term markets have a positive influence on the availability depending on the penalty scheme for non-performance.

\subsection{Technical concerns about process handling}

Besides the availability of reserve capacity and energy, also the actual process handling of connecting the reserve capacity into the control loop is crucial. ${ }^{27}$ Shorter contract durations lead to frequent changes from which plants and in which order reserve capacity is to be called. It requires re-programming the AGC, which involves costs and risks of failures if not done automatically. Given the technical progress of information technology, a necessary automation of this process should be straightforward. However, even today the TSOs seem to be able to handle the short-term re-allocation of reserve capacity without any problems. At least the fact that TSOs only require a minimum availability of 4 hours for secondary reserve provision from pumped storage implies that the TSOs are able to handle short-term reallocations. In cases of unforeseen plant outages the reserve capacity has anyhow to be provided from back-up capacity, which has to be connected into the control loop on rather short-hand notice. Hence short-term re-programming is even occurring in today's system.

Another problem which has to be managed in the process handling is the changeover of reserve energy generation from one plant to another one at the end/beginning of a provision period. The provided reserve energy has to be reduced in one plant and increased in another plant. It is often claimed that lacking synchronization might impede the necessary effective balancing. The shorter the contract duration, the more such situations potentially occur. However, such situations of "breaks" and changeovers are omnipresent in the electricity system. Plants are ramping up or down every hour or even 15 minutes according to their predefined generation schedule. The resulting changes in the load-flow have to be counterbalanced by ramping up or down of additional secondary reserve capacity. These situations are usually unproblematic.

Furthermore, the system security is not particularly compromised during the currently necessary changeovers; otherwise the existing practice would have to be re-considered. TSOs

\footnotetext{
${ }^{26}$ There are no bid insufficiencies reported for regulacion secundaria in Spain. In California, the bid volume for regulation and spinning reserve is on average twice as high as the demand, showing that the incentive mechanism for offering works generally very well. In few individual hours (1.3 to $1.8 \%$ of all hours) bid insufficiencies appeared in 2006 (CAISO, 2007), which are mostly attributable to the fact that in water-rich periods hydro plants displaced thermal ones. As the thermal plants were not online they could not provide the required amount of thermal reserve capacity.

In Norway, a reserve option market (ROM) was introduced in 2000 to circumvent reserve inadequacies for tertiary reserve as a result of an overall supply shortage. All successful bids in the ROM commit themselves to offer reserve energy in the short-term balancing market. The balancing market alone would have incentive problems to attract enough offers since only the actually used reserve energy is remunerated, which might make offering unattractive and risky. Bid insufficiencies are also more likely in scarcity situations because the balancing market is held after the Elspot market. In the initial tendering rounds of the ROM, the bidders could engage in either 3-month or 1-year contracts. The majority of the bidders chose a duration of 3-months, presumably for flexibility reasons as explained in section 4 . The Norwegian TSO reduced the option contracts to only one week in 2004, recognizing the advantages of a better foresight (see Wangensteen, 2005).

${ }^{27}$ Due to the decentralized nature of primary control, this problem arises mostly for secondary control. Though, the governor control has to be adjusted locally by the plant operator also in the case of primary reserve.
} 
in countries with shorter contract durations or co-optimization seem to be able to handle the technical challenges of continuous changeovers.

Overall, the suspected security risks appear not to be overwhelming and it should be possible to manage them appropriately.

\section{CONCLUSION}

This paper provides a theoretical foundation and simulation results for the discussion of appropriate contract durations for primary and secondary reserve capacity auctions in the context of the German/European market design that generally relies on multiple bilateral markets. Reserve capacity markets are held separately from any other electricity market. This is a crucial difference compared to the central coordination in pool markets, which cooptimize reserve capacity provision and spot energy.

The results clearly show that shorter periods with the crucial feature of lower variations of the marginal spot plants along the merit order lead to more efficient market outcomes. Competitive market prices would be lower due to a more efficient dispatch. Not only would prices in the reserve capacity market decrease, but also spot market prices. Even if the spot market prices change only little in relative terms, the large volume leverage leads to a significant overall effect. This interdependency effect seems to be often overlooked when discussing market design issues for system reserve capacity. Under longer, "inefficient" contract durations, this effect can be partly reaped by the owners of large generation portfolios by re-assigning reserve capacity to different plants. Thus, it implies a discrimination of smaller generation companies, potentially leading to market deterrence. Additionally, smaller generation companies have disadvantages resulting from relatively higher risk costs due to non-availability and less flexibility concerning planned outages.

Compared to the expected efficiency gains, the increase in transaction costs is rather insignificant. Suspected security risks do not appear to be predominant and could be managed appropriately by a higher degree of automation. The opportunity costs character of reserving capacity implies that a higher expected profit can be earned in this market compared to the spot market (or other alternatives). Hence, enough incentives exist to ensure sufficient supply both short- and long-term.

The analysis shows that the latest changes towards monthly auctions for secondary reserve capacity in Germany have only a limited positive effect compared to daily 4-hour or hourly auctions. The missing distinction between peak/off-peak periods in the monthly auctions for primary reserve capacity in the latest specifications might even led to a considerable negative effect on the market results. The whole analysis makes a strong case for shorter contract durations or at least for more profound decisions on appropriate product definitions.

The recent ownership changes of two of the German TSOs (E.ON and Vattenfall Europe transmission grids were sold to the Dutch TSO Tennet in 2009 and Belgian TSO Elia in 2010, respectively) is an interesting opportunity to revive the regulatory discussion about the market design and the appropriate contract duration for reserve capacity in particular. The interests of the fully-unbundled TSOs Tennet and Elia are distinctively different than those of the integrated companies E.ON and Vattenfall with large generation portfolios and only legally unbundled TSOs. The regulator might even think about adapting the yard-stick regulation with respect to "non-influenceable" costs. As TSOs have an influence on their procurement costs for reserve capacity through changes in market design, they should get an explicit incentive to cooperatively improve the market design with the regulator. This better alignment of interest might change the discussion between the TSOs and the regulator and thus allow improvements in the market design. 
The market design of a pool market with co-optimization of spot energy and reserve capacity provision can be seen as an extreme case of short contract duration. It would ensure a fully efficient resource dispatch. However, a change in the macro market structure from decentral bilateral markets to a pool market should be driven by many other factors beyond the reserve capacity perspective. 


\section{APPENDIX 1: Parameters for the market simulation}

The analysis is based on data estimated for the year 2006. The parameters needed are mostly not publicly available and are the best estimates we can obtain.

\section{Spot electricity demand}

The hourly load data published by the UCTE is linearly adjusted to fit the annual net production from public generators in Germany (UCTE, 2007 and BMWi, 2007). In a further step, the corresponding day-ahead wind forecast is deducted. This "expected residual load curve" is approximately the electricity demand the operators of conventional plants have to consider when submitting the bids in the reserve market.

This data is selectively used to reflect the respective periods chosen as contract period for the reserve market. The resulting empirical demand distributions are used for the further analysis of the cases 1 to 3. For the expected residual load data also the demand variation over a 4hour-period (case 4) can be estimated. The deviation from the average residual load for all 4hour-periods is depicted in Figure 10. The deviation is uncorrelated with the average residual load. A regular triangle distribution with a dispersion of $\pm 5,000 \mathrm{MW}$ around the average is supposed to represent the demand variation.

The demand uncertainty the bidders face in the hourly case is supposed to follow a regular triangle distribution with a dispersion of $\pm 1.5 \%$. When submitting their reserve bids, i. e. before bidding in the spot market, the bidders do not know exactly how much will be requested in the spot market. This is partly due to the private information about the forecasted demand by the load serving entities and the limited demand elasticity. The actual demand uncertainty cannot be estimated from available data, thus we decided to choose a reasonable assumption. Note, that this demand uncertainty is different from the load forecast error. The first is the uncertainty how much generation capacity needs to be scheduled to meet the demand in the spot market and the later describes how much the actual real-time demand deviates from the spot market schedule.
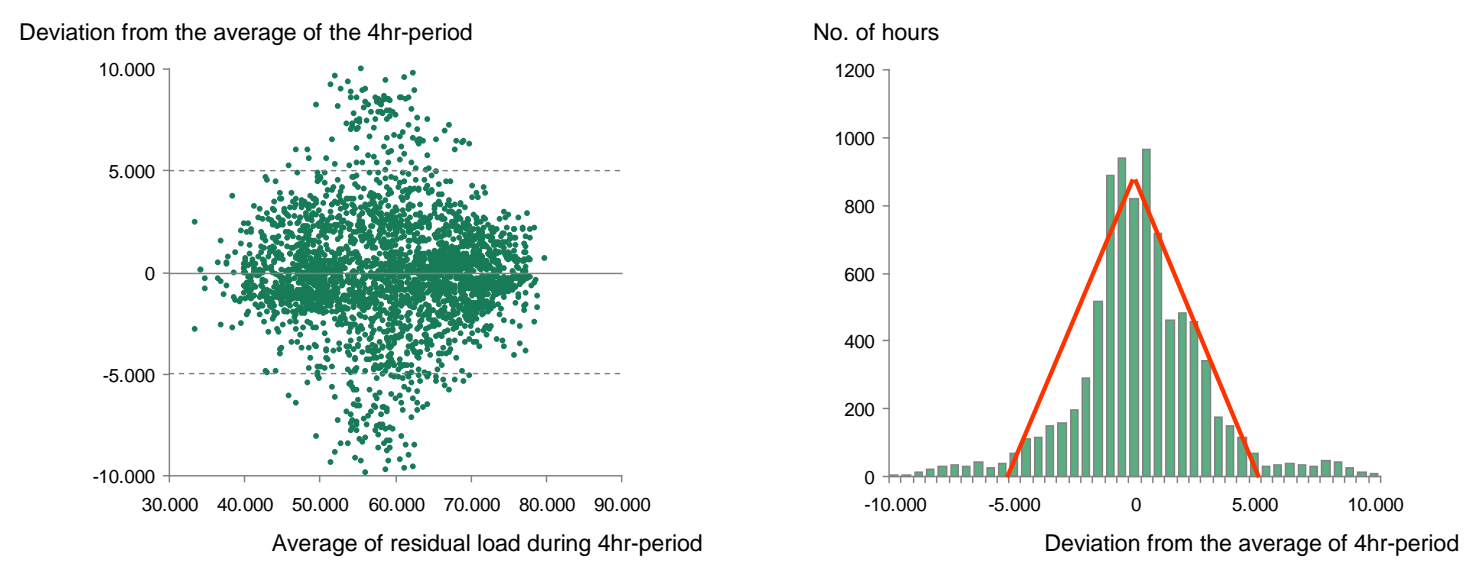

FIGURE 7: SPOT DEMAND VARIATION DURING 4 HOUR-PERIODS

\section{Supply structure}

The effective spot market supply curve for 2006 is estimated by regressing the hourly EEX spot price by the hourly residual load. Since the wind forecast is deducted from the load, the resulting supply curve describes only the "more stable part" of the merit order net of any wind generation capacity. The price-volume relationship is best approximated by a power function 
in the form of $a x^{n}$. To restrict ourselves to the ordinary conditions, all hours with prices below $10 € / \mathrm{MWh}$ and above than $200 € / \mathrm{MWh}$ are excluded. The fit of the estimation is relatively good with $\mathrm{R}^{2}=0.77$, implying that more than three quarter of the price variance can be explained by variations in the demand. The parameters are approximately $a=5 * 10^{-6}$ and $n=$ 2.50 .

The frequently discussed issue whether the German spot market is sufficiently competitive and whether the prices reflect marginal generation costs is not subject of this paper. It should be also noted that the estimated spot supply curve corresponds rather to - in the terms of this paper - the transformed spot supply function than to the short-run marginal cost function $C(x)$. This is omitted in the analysis and it is used as an estimate for $C(x)$ in order not to preclude the impact of the secondary reserve capacity on the spot market.

For stable and effective operation of thermal power plants, their load level usually needs to be above a certain minimum level, which is usually in a range of $40-60 \%$ of the nameplate capacity. In the following a $k^{\text {Min }}$ of $50 \%$ is assumed. The load adjustment rates per minute of thermal plants are $1-5 \%$ for nuclear, $1-2 \%$ for lignite, $2-4 \%$ for coal and about $8 \%$ for gas turbines (see Swider, 2006). For secondary reserve mostly coal and CCGT plants are used, resulting in about $10-40 \%$ adjustable capacity share within the 5 minute required respond time. Therefore an average of $k^{S R P}=20 \%$ is chosen. For primary reserve a capacity share $k^{P R P}$ of $5 \%$ seems to be appropriate.

\section{Reserve power demand}

The total demand for incremental secondary reserve capacity in 2006 was 3,330 MW (see Table 1). From the balancing data (minus the called tertiary reserve) for the four TSOs, the demand distribution for the actual incremental secondary reserve energy employed can be estimated. For 2006, it follows indeed roughly a normal distribution with a mean of 19 MW and a standard deviation of 1,080 MW.

The total demand for primary reserve capacity in 2006 was 657 MW. 


\section{REFERENCES}

BKartA, 2000. Ruling on the RWE/VEW merger by the German Competition Authority (in German), B8309/99-RWE/VEW of 03.07.2000. Online: www.bundeskartellamt.de.

BMWi, 2007. Electricity production and consumption data for Germany. Online: www.bmwi.de.

BNetzA, 2007. Ruling on the Auction procedures for Primary and Secondary Reserve Capacity, B6-06-065 and B6-06-066 of 31.08.2007. Online: www.bundesnetzagentur.de.

Bower, J., Bunn, D., 2001. Experimental Analysis of the Efficiency of Uniform-price versus Discriminatory Auctions in the England and Wales Electricity Market. Journal of Economic Dynamics and Control 25, 561-592.

Buechner, J., Tuerkucar, T., 2005. Options for Development of the Power System Reserve Markets in Germany (in German). Energiewirtschaft 104, 54-57.

Bunn, D., Bower, J., 2000. Model-based Comparisons of Pool and Bilateral Markets for Electricity. Energy Journal 21, 1-29.

Bushnell, J., Oren. S.S., 1994. Bidder Cost Revelation in Electric Power Auctions. Journal of Regulatory Economics 6, 5-26.

CAISO, 2005. Operating Procedures: Ancillary Service Procurement Version 6.1. Online: www.caiso.com.

CAISO, 2007. Annual report on Market Issues and Performance 2006. Online: www.caiso.com.

Chao, H., Wilson, R., 2002. Multi-Dimensional Procurement Auctions for Power Reserves: Robust IncentiveCompatible Scoring and Settlement Rules. Journal of Regulatory Economics 22, 161-183.

Crampton, P., Chao, H., Wilson, R., 2005. Review of the Proposed Reserve Markets in New England. White paper. Online: www.cramton.umd.edu.

Elia, 2006. Note Concerning the Mechanism for Managing the Balance of the Elia Control Area. Version 1.2. Online: www.elia.be.

ETSO, 2003. Current State of Balance Management in Europe. Online: www.etso-net.org.

Fabra, N., von der Fehr, N-H., Harbord, D., 2006. Designing Electricity Auctions. Rand Journal of Economics 37, 23-46.

Federico, G. Rahman, D., 2003. Bidding in Electricity Pay-As-Bid Auctions. Journal of Regulatory Economics $24,175-211$.

Heise, J., 2007. The Role and Potential of Interruptible Load as Tertiary Reserve in the German Reserve Market: A Survey among Industrial Consumers. Presentation, $9^{\text {th }}$ IAEE European Energy Conference, Florence.

Joskow, P., Tirole, J., 2007. Reliability and competitive electricity markets, Rand Journal of Economics 38, 6084.

Just, S., Weber, C., 2008, Pricing of Reserves: Valuing System Reserve Capacity against Spot Prices in Electricity Markets, Energy Economics 30, 3198-3221.

Kamat, R., Oren, S.S., 2002. Rational Buyer meets Rational Seller: Reserve Market Equilibria under Alternative Auction Designs. Journal of Regulatory Economics 21, 247-288.

Kiener, E., 2006. Analysis of Balancing Markets. Master thesis, KTH Stockholm, School of Electrical Engineering, Sweden.

Kraftnät, 2006. Balance Obligation Agreement with Balance Regulation. Online: www.svk.se.

Mansur, E.T., White, M. W., 2009. Market Organization and Efficiency in Electricity Markets. Working paper. Online: http://www.som.yale.edu/faculty/etm7/papers/mansur_white_pjmaep.pdf.

Mount, T.D., Thomas, R.J., Vossler, C.A., Zimmerman, R.D., 2002. Experimental Evidence about the Persistence of High Prices in a Soft-Cap Auction for Electricity. Proceedings $25^{\text {th }}$ International IAEE Conference, Aberdeen, 2002.

Ockenfels, A., Grimm, V., Zoettl, G., 2008. Electricity Market Design. Report for the Saxon Exchange Supervisory Authority. Online: www.eex.com.

Rassenti, S.J., Smith, V.L., Wilson, B. J., 2003. Discriminatory Price Auctions in Electricity Markets: Low Volatility at the Expense of High Price Levels. Journal of Regulatory Economics 23, 109-123. 
Rebours, Y.G., Kirschen, D.S., Trotignon, M., Rossignol, S., 2007. A Survey of Frequency and Voltage Control Ancillary Services - Part II: Economic Features. IEEE Transactions on Power Systems 22(1), 358-366.

Regelleistung, 2009. Common internet platform of reserve power auctions of the four German TSOs (in German). Online: www.regelleistung.net.

Singh, H., Papalexopoulos, A., 1999. Competitive Procurement of Ancillary Services by an Independent System Operator. IEEE Transactions on Power Systems 14, 498-504.

Stoft, S., 2002. Power System Economics - Designing Markets for Electricity. Wiley IEEE Press, Piscataway, NJ.

Swider, D.J., 2004. Background study - Balancing system in Germany, Working Package 4 of the GreenNet Project "Pushing a Least Cost Integration of Green Electricity into the European Grid". Online: www.greennet.at.

Swider, D.J., 2007a. Competition in the German Market for Power Systems Reserve? (in German). Energiewirtschaftliche Tagesfragen 57(9), 32-37.

Swider, D.J., 2007b. Efficient scoring-rule in multipart procurement auctions for power systems reserve. IEEE Transactions on Power Systems 22(4): 1717-1725.

Swider, D.J., 2006. Trading on Markets for Power Systems Reserve and Spot Energy (in German). PhD dissertation, University of Stuttgart.

Swider, D.J., Ellersdorfer, I., 2005. Cost Efficiency in the German Market for Power Systems Reserve (in German). Energiewirtschaftliche Tagesfragen 55, 802-806.

Swider, D.J., Weber, C., 2003. Design of German Markets for Power Systems Reserve (in German). Energiewirtschaftliche Tagesfragen 53, 448-453.

UCTE, 2004. Operation Handbook. Online: www.ucte.org.

UCTE, 2007. Hourly load values. Online: www.ucte.org.

Wawer, T., 2005. Efficient Design of Auctions for Power Systems Reserve for Reducing Transmission Charges (in German). Proceedings of $4^{\text {th }}$ IEWT Conference, Vienna, 2005.

Wangensteen, I., 2005. Power Markets. Online: www.fer.hr/_download/repository/KompendiumTET4185nov05\%20justert-4.pdf

Weidlich, A., Veit, D., 2006. Bidding in Interrelated Day-ahead Electricity Markets: Insights from an Agentbased Simulation Model. Proceedings of the 29th IAEE International Conference, Potsdam, 2006.

Wilson, R., 2002. Architecture of Power Markets. Econometrica 70, 1229-1241. 